\title{
SNHG15 is a bifunctional MYC-regulated noncoding locus encoding a IncRNA that promotes cell proliferation, invasion and drug resistance in colorectal cancer by interacting with AIF
}

Morvarid Saeinasab ${ }^{1,2}$, Ahmad Reza Bahrami 1,2, Jovanna González ${ }^{3,4}$, Francesco P. Marchese ${ }^{3,4}$, Dannys Martinez ${ }^{3,4}$, Seyed Javad Mowla ${ }^{5}$, Maryam M. Matin ${ }^{1,2^{*}}$ and Maite Huarte ${ }^{3,4^{*}}$

\begin{abstract}
Background: Thousands of long noncoding RNAs (IncRNAs) are aberrantly expressed in various types of cancers, however our understanding of their role in the disease is still very limited.

Methods: We applied RNAseq analysis from patient-derived data with validation in independent cohort of patients. We followed these studies with gene regulation analysis as well as experimental dissection of the role of the identified IncRNA by multiple in vitro and in vivo methods.

Results: We analyzed RNA-seq data from tumors of 456 CRC patients compared to normal samples, and identified SNHG15 as a potentially oncogenic IncRNA that encodes a snoRNA in one of its introns. The processed SNHG15 is overexpressed in CRC tumors and its expression is highly correlated with poor survival of patients. Interestingly, SNHG15 is more highly expressed in tumors with high levels of MYC expression, while MYC protein binds to two Ebox motifs on SNHG15 sequence, indicating that SNHG15 transcription is directly regulated by the oncogene MYC. The depletion of SNHG15 by siRNA or CRISPR-Cas9 inhibits cell proliferation and invasion, decreases colony formation as well as the tumorigenic capacity of CRC cells, whereas its overexpression leads to opposite effects. Gene expression analysis performed upon SNHG15 inhibition showed changes in multiple relevant genes implicated in cancer progression, including MYC, NRAS, BAG3 or ERBB3. Several of these genes are functionally related to AIF, a protein that we found to specifically interact with SNHG15, suggesting that the SNHG15 acts, at least in part, by regulating the activity of AIF. Interestingly, ROS levels, which are directly regulated by AIF, show a significant reduction in SNHG15-depleted cells. Moreover, knockdown of SNHG15 increases the sensitiveness of the cells to 5-FU, while its overexpression renders them more resistant to the chemotherapeutic drug.
\end{abstract}

Conclusion: Altogether, these results describe an important role of SNHG15 in promoting colon cancer and mediating drug resistance, suggesting its potential as prognostic marker and target for RNA-based therapies.

Keywords: SNHG15, Colorectal cancer, IncRNA, Survival, Drug resistance, AIF

\footnotetext{
*Correspondence: matin@um.ac.ir; maitehuarte@unav.es

'Department of Biology, Faculty of Science, Ferdowsi University of Mashhad,

Mashhad, Iran

${ }^{3}$ Department of Gene Therapy and Regulation of Gene Expression, Center for

Applied Medical Research, University of Navarra, Pamplona, Spain

Full list of author information is available at the end of the article
}

(c) The Author(s). 2019 Open Access This article is distributed under the terms of the Creative Commons Attribution 4.0 International License (http://creativecommons.org/licenses/by/4.0/), which permits unrestricted use, distribution, and reproduction in any medium, provided you give appropriate credit to the original author(s) and the source, provide a link to the Creative Commons license, and indicate if changes were made. The Creative Commons Public Domain Dedication waiver (http://creativecommons.org/publicdomain/zero/1.0/) applies to the data made available in this article, unless otherwise stated. 


\section{Background}

In the past years, advances in sequencing revealed that only $1-2 \%$ of the human genome encodes for proteins while the majority of it is transcribed into non-coding RNAs (ncRNAs) [1]. Different classes of ncRNAs are expressed in diverse biological processes and cellular pathways, including small ncRNAs (miRNAs, piRNAs and siRNAs) and long ncRNAs, which have at least 200 nucleotides of length and can be spliced [2-5]. LncRNAs can be classified into various categories based on their position relative to protein-coding genes: (1) intronic, when they are located within genes; (2) intergenic, when they are mapped between different genes and (3) antisense, when they are overlapping with exons of other transcript on the opposite strand [6]. The functional roles of these molecules remain mostly unclear, but recent studies have revealed that they contribute to various cellular processes such as transcription regulation, nuclear architecture, epigenetic regulation, enhancer association (in nucleus), maintenance of mRNA stability, sponging microRNA or regulation of protein translation (in cytoplasm) [7]. Recently, by next-generation sequencing, thousands of lncRNAs have been found to be aberrantly expressed in various types of cancers [8]. While some of them may play oncogenic roles promoting proliferation, invasion and metastasis, others may have a tumor suppressor function, by modulating growth arrest pathways [9-11].

According to global cancer statistics, colorectal cancer (CRC) is the third most common human malignancy and the fourth leading cause of cancer-associated mortality $[12,13]$. Therefore, its early diagnosis is an essential requirement. Several studies have reported that some lncRNAs are associated with different stages of CRC $[14,15]$, indicating that IncRNAs could be a biomarker or target for diagnostic, prognostic and therapeutic applications. However, the contribution of long noncoding RNAs to this type of cancer is still poorly studied.

In the present study, we identify and characterize the oncogenic lncRNA SNHG15, which is correlated to survival of CRC patients. Our results describe an important effect of SNHG15 in cancerous phenotype of CRC cells and its role in drug sensitivity. Moreover, several genes deregulated after SNHG15 depletion are implicated in cancer initiation, progression and also survival pathways. Altogether, these findings suggest the potential of SNHG15 as prognostic marker and target for RNA-based therapies.

\section{Methods}

\section{TCGA analysis}

The RNA-seq data of 456 tumor and 41 normal samples were downloaded from TCGA database (https:// cancergenome.nih.gov/). The expression of lncRNAs was quantified by Cufflinks v.2.2.1 and lncRNA expression levels were compared between normal tissue and tumor tissue samples.

\section{Patients}

Fresh CRC specimens and their adjacent normal tissues were obtained from $36 \mathrm{CRC}$ patients who underwent surgeries between 2014 and 2016 in Imam-Reza Hospital, Mashhad, Iran. None of patients had received preoperative treatment including radiotherapy or chemotherapy and all of samples were confirmed as colorectal cancer after histopathological examination. The study protocol was approved by the Ethics Committee of Ferdowsi University of Mashhad and all patients were informed with a written for using their tissues. All clinicopathological characteristics of patients are presented in Table 1 .

\section{Cell lines and cell culture}

Human colorectal cancer cell lines DLD1, HCT 116, HT-29, LoVo, LS513, SW620 and T84 were cultured in Roswell Park Memorial Institute (RPMI-1640) medium (Gibco) supplemented with $10 \%$ fetal bovine serum (FBS, Gibco) and 1\% penicillin/streptomycin (Lonza). RKO, SW480 and Caco-2 cells were cultured in Dulbecco's Modified Eagle Medium (DMEM, Gibco) supplemented with $10 \% \mathrm{FBS}$ and $1 \%$ penicillin/streptomycin. Primary dermal fibroblasts (HDFa) were cultured in High glucose Dulbecco's Modified Eagle Medium (DMEM, Gibco) supplemented with 15\% FBS and 1\%

Table 1 Clinicopathological characteristics of CRC patients

\begin{tabular}{lll}
\hline Clinical parameter & Number & Percentage \\
\hline Age & 13 & 36.1 \\
$<60$ & 23 & 63.9 \\
Gender & & \\
Male & 17 & 47.2 \\
Female & 19 & 52.8 \\
Invasion depth & & \\
T1 & 2 & 5.6 \\
T2 & 4 & 11.1 \\
T3 & 29 & 80.6 \\
T4 & 1 & 2.7 \\
TNM stages & & \\
I & 3 & 8.3 \\
II & 33 & 91.7 \\
II \& IV & 0 & 0 \\
Lymphatic metastasis & & 50 \\
Yes & 18 & 50 \\
No & 18 & \\
\hline
\end{tabular}


penicillin/streptomycin. All cell lines were obtained from American Type Culture Collection (ATCC). Cells were maintained in $5 \% \mathrm{CO} 2$ humidified-air at $37^{\circ} \mathrm{C}$.

\section{RNA extraction and qRT-PCR}

Total RNAs were isolated from patient specimens and cultured cells using TRIzol Reagent (Invitrogen) following the manufacturer's instructions. After DNase I (Invitrogen) treatment, cDNAs were synthesized using High-Capacity cDNA Reverse Transcription Kit (Applied Biosystem) with random hexamer primers. qRT-PCRs were performed using SYBR Green reagent (Applied Biosystem). Expression levels of genes were calculated with the comparative cycle threshold (CT) (2- $\Delta C \mathrm{~T}$ and 2- $\Delta \Delta \mathrm{CT}$ ) method using glyceraldehyde 3-phosphate dehydrogenase (GAPDH) as an endogenous control. All primers used in the study are listed in Additional file 1: Table S1.

\section{Cell transient transfection}

All siRNAs for targeting SNHG15 and MYC and negative control siRNA were purchased from Sigma-Aldrich (USA). LoVo and SW620 cells were plated into 6 well plate $\left(150 \times 10^{3}\right.$ cells per well $)$ and transfected with siRNAs at a final concentration of $25 \mathrm{nM}$ for $48 \mathrm{~h}$, using Lipofectamine 2000 (Invitrogen, USA) according to manufacturer's protocol. The sequence of siRNAs are as follows: SNHG15\#1 (Sense: 5'-CCUUGAGUCUCAUG UUCAA-3', Anti-sense: 5' - UUGAACAUGAGACU CAAGG-3'), SNHG15\#2 (Sense: 5'- GAGCUUACU GUCACAGCAA-3', Anti-sense: 5' - UUGCUGUGA CAGUAAGCUC-3'), MYC (Sense: 5'- GGUCAGAGU CUGGAUCACC-3', Anti-sense: 5'- GGUGAUCCA GACUCUGACC-3'), Ctrl (Sense: 5' - CAGUCGCGU UUGCGACUGGC-3', Anti-sense: 5' - GCCAGUCGC AAACGCGACUG-3').

For overexpression of SNHG15, we purchased SNHG15 cDNA sequence (837 bp) was cloned in pDNR-LIB (BC092459; Source Bioscience-UK) and subcloned it into pcDNA3.1 plasmid. Then pcDNA3.1 vectors (empty vector and SNHG15) were transfected into HCT 116 and SW480 cells $\left(300 \times 10^{3}\right.$ cells per well $)$ at final concentration $250 \mathrm{ng} / \mathrm{mL}$ using Lipofectamine 2000 and subsequent studies were done after $48 \mathrm{~h}$.

\section{Polysome fractionation}

LoVo cells were cultured in $15 \mathrm{~cm}$ dishes one day before experiment to reach $80 \%$ confluency. The day after, one plate was treated with cycloheximide $(100 \mu \mathrm{g} / \mathrm{mL})$ and another one treated with EDTA $(25 \mathrm{mM})$ to disassemble the polysomes as negative control followed by incubation at $37^{\circ} \mathrm{C}$ for $5 \mathrm{~min}$. After removing media and washing 3 times with PBS, cells were harvested by scrapping and transferred to $15-\mathrm{mL}$ tubes for centrifugation
(200 $\times g$ for $5 \mathrm{~min})$. Cell pellets were resuspended in $425 \mu \mathrm{L}$ of a hypotonic buffer [ $5 \mathrm{mM}$ Tris- $\mathrm{HCl}(\mathrm{pH} 7.5)$, $1.5 \mathrm{mM} \mathrm{KCl}, 2.5 \mathrm{mM} \mathrm{MgCl}_{2}$ and $1 \mathrm{X}$ protease inhibitor cocktail], followed by adding $5 \mu \mathrm{L}$ of $10 \mathrm{mg} / \mathrm{mL} \mathrm{CHX} \mathrm{or}$ EDTA, $1 \mu \mathrm{L}$ of $1 \mathrm{M}$ DTT and 100 units of RNase inhibitor and vortexed for $5 \mathrm{~s}$. Then $25 \mu \mathrm{L}$ of $10 \%$ Triton X-100 and $25 \mu$ Lof $10 \%$ sodium deoxycholate were added and vortexed for $5 \mathrm{~s}$ again. Cell lysates were centrifuged at $16000 \times g$ for $7 \mathrm{~min}$ at $4{ }^{\circ} \mathrm{C}$ and supernatants $(\sim 500 \mu \mathrm{l})$ were loaded onto sucrose gradient. Ultracentrifuge was performed at $33000 \mathrm{rpm}$ for $150 \mathrm{~min}$ at $4{ }^{\circ} \mathrm{C}$ using Optima L-100 XP Ultracentrifuge (BECKMAN) with SW41Ti rotor. 12 fractions were separated carefully and transferred into $2 \mathrm{~mL}$ tubes. $1 \mathrm{~mL}$ TRIzol Reagent was added to each fraction and RNA extraction was performed according to manufacturer's instructions. Expression levels of SNHG15 in each fraction were quantified by qRT-PCR and normalized relative to the first fraction collected. Also GAPDH expression was evaluated as a translated mRNA (positive control).

\section{Cell proliferation and Colony formation assay}

Transfected cells were plated in 96-well plates at a density of $1 \times 10^{3}$ cells per well. Then cell proliferation was evaluated using CellTiter96 Aqueous Non-Radioactive Cell Proliferation Assay (MTS) kit (Promega) every $24 \mathrm{~h}$.

For colony formation assay, transfected cells $\left(0.5 \times 10^{3}\right.$ cells per well) were seeded in a six-well plate. After 10 days, colonies were fixed with $0.5 \%$ Glutaraldehyde (Sigma) for $20 \mathrm{~min}$ and subsequently washed with PBS for 3 times. Then stained for $30 \mathrm{~min}$ with $0.5 \%$ crystal violet (Sigma) and the number of colonies was counted in each well.

\section{Cell-cycle and apoptosis assays}

For cell-cycle analysis, transfected cells were harvested after $48 \mathrm{~h}$ and stained with propidium iodide. Cell cycle assay was performed in a FACSCalibur flow cytometer (BD Biosciences) and data were analyzed by BD CellQuest and Flow Jo software. For time-line studies, G1/S synchronized cells were generated by double thymidine block procedure. Briefly, cells were grown in medium containing $2 \mathrm{mM}$ thymidine for $16 \mathrm{~h}$. Then cultured in normal medium for $9 \mathrm{~h}$ followed by $16 \mathrm{~h}$ incubation in presence of $2 \mathrm{mM}$ thymidine again.

Apoptosis assay was performed by Annexin $\mathrm{V}$ and 7-AAD staining using Apoptosis Detection Kit I (BD Biosciences) according to manufacturer's instructions and detected by FACSCalibur flowcytometer.

\section{Transwell invasion assay}

For invasion assay, the upper side of 8 - $\mu \mathrm{m}$ pore-size transwell inserts (Corning) were precoated with type I rat tail collagen (Croning) and then Matrigel (BD, Biosciences) 
was diluted with PBS $(3 \mathrm{mg} / \mathrm{mL})$ and polymerized at $37^{\circ} \mathrm{C}$ for $2 \mathrm{~h} .48 \mathrm{~h}$ after transfection, $10^{5} \mathrm{CRC}$ cells (LoVo or HCT116) in $100 \mu \mathrm{L}$ of medium containing $1 \%$ FBS, were plated onto the upper side of inserts and after $4 \mathrm{~h}, 300 \mu \mathrm{L}$ of medium containing 10\% FBS was added to the lower chamber to induce cell attraction. Plates were incubated at $37^{\circ} \mathrm{C}$ for 48 . Then cells were fixed in $4 \%$ formaldehyde for $20 \mathrm{~min}$ and non-invading cells on the upper side of the insert were removed with cotton swabs. The lower part of the insert was stained with $0.1 \%$ crystal violet (Sigma). Images were captured from four fields in each well using the Leica DMIL LED inverted microscope (Leica Microsystems) and the numbers of invasive cells were counted from five random fields in each image. Experiments were performed independently at least three times.

\section{Mouse xenograft experiments}

Female BALB/c-Rag2/-IL2cc/immunodeficient mice aged 6-7 weeks were used in this study. The study was performed under specific pathogen-free conditions at Center of Medical Application (CIMA) University of Navarra, Spain. For each mice, $1 \times 10^{6}$ SNHG15 overexpressing HCT 116 and HCT116 transfected with an empty vector were resuspended in $100 \mu \mathrm{L}$ PBS and mixed with the same amount of Matrigel to inject subcutaneously into the hind limb. Tumor size was measured externally every 4 days using a precision caliper for a total period of 28 days. Tumor volume $(\mathrm{V})$ was estimated using the following formula: $\mathrm{V}=\pi / 6 \times$ width $^{2} \times$ length. The tumor weight was measured on the last day after removal.

For LoVo cells, after CRISPR-Cas9 editing, $4 \times 10^{6}$ cells were injected per mice and tumor size was measured every 4 days. After 48 days, tumors were dissected out and their weight were measured.

\section{CRISPR-Cas9 editing}

Two single-guide RNAs (sgRNAs) were designed to delete the region between exon 3 to 5 of SNHG15 using a tool from the Zhang Lab (http://crispr.mit.edu/). Oligonucleotides to clone the guide RNA (Additional file 2: Table S2) were then annealed and cloned into pX330 vector containing CAS9 [16] and subsequently co-transfected with GFP expressing plasmid (pmax-GFP) into LoVo cells. GFP positive cells were sorted in 96 well plate by BD FACSAria IIu cytometer. After single cells reached confluency, genomic DNA was extracted using QuickExtract reagent (Epicentre) and PCR was performed using a pair of primers flanking the depleted region and positive clones were identified by PCR product length. Furthermore, RNA was extracted to perform qRT-PCR by specific primer (Primer pair 1 and 2) to validate deletion of aimed region. After selecting clones (WT3, CL10 and CL83), subsequent experiment (cell proliferation, colony formation, cell cycle, apoptosis assay and tumor formation) were performed as described before.

\section{Nuclear-cytoplasmic fractionation}

Cells were cultured in $10 \mathrm{~cm}$ dishes and harvested into two tubes for subcellular fractions and whole-cell extraction. After centrifugation at $1000 \times g$ for $5 \mathrm{~min}$ at $4{ }^{\circ} \mathrm{C}$, cell pellets were resuspended in $500 \mu \mathrm{L}$ of lysis buffer $(10 \mathrm{mM}$ Tris- $\mathrm{HCl}, \quad \mathrm{pH} 7.5,140 \mathrm{mM} \mathrm{NaCl}, 1.5 \mathrm{mM}$ $\mathrm{MgCl}_{2}, 0.05 \%$ IGEPAL supplemented with RNasin $10 \mathrm{U} /$ $\mathrm{mL}$ and protease inhibitor cocktail) and incubated on ice for $10 \mathrm{~min}$. Then TRIzol Reagent was added to one tube containing cell lysate to extract total RNA. For obtaining nuclear and cytoplasmic fractions, $500 \mu \mathrm{L}$ of lysis buffer containing sucrose was added into a clean tube and cell lysate was added to this tube without mixing the two phases. After $10 \mathrm{~min}$ centrifugation at $12000 \times g$ and $4{ }^{\circ} \mathrm{C}$, around $500 \mu \mathrm{L}$ of the upper phase was collected as cytoplasmic fraction. Remaining pellet was resuspended in $500 \mu \mathrm{L}$ of lysis buffer as nuclear fraction and finally cytoplasmic and nuclear RNAs were extracted using TRIzol Reagent.

\section{RNA pull-down}

RNA pull-down was performed as described previously [17]. Briefly, biotinylated RNA of SNHG15 was generated in vitro and incubated with protein lysate of LoVo cells and then streptavidin magnetic beads. Interacting proteins were loaded in a NuPAGE Novex 4-12\% bis-Tris gel (Invitrogen) and stained with SilverQuest Silver Staining Kit (ThermoFisher). One differential band was seen and sent for mass spectrometry to Taplin Mass Spectrometry Facility (Harvard Medical School; USA).

\section{Western blot}

Cells were harvested and lysed in RIPA buffer (150 mM $\mathrm{NaCl}, 0.5 \%$ sodium deoxycholate (Sigma), 0.1\% SDS (Sigma), $50 \mathrm{mM}$ Tris-HCl (pH 7.4), $150 \mathrm{mM} \mathrm{NaCl}$ (Sigma)) containing protease Inhibitor Cocktail (Roche Applied Science) for $15 \mathrm{~min}$ on ice. Cell lysate was centrifuged at $16000 \times g$ at $4{ }^{\circ} \mathrm{C}$ for $15 \mathrm{~min}$ and protein concentration was measured by Pierce BCA Protein assay kit (ThermoFisher). Equal amounts of proteins were loaded on a $10 \%$ SDS-PAG and after separation by electrophoresis, transferred onto nitrocellulose membranes (Bio-Rad). Membranes were then blocked in 5\% non-fat milk for $1 \mathrm{~h}$ at RT and immunoblotted by overnight incubation at $4{ }^{\circ} \mathrm{C}$ with the indicated anti-AIF primary antibody (1:1000; sc-13,116; Santa Cruz). After three washes with PBS-Tween (0.1\%), the membranes were incubated with anti-mouse secondary antibody: anti-IgG (1:2000; sc-2025; Cell Signaling) for $1 \mathrm{~h}$ at RT. Finally, the protein bands were visualized using an Enhanced Chemiluminescence Detection kit (Perkin Elmer, Waltham, MA, USA). 


\section{RNA immunoprecipitation (RIP)}

LoVo cells were cultured in $10 \mathrm{~cm}$ dishes and then harvested to prepare cell lysate by RIPA buffer. After centrifugation, cytoplasmic fraction was collected and pre-cleared with Protein G beads (Invitrogen). Five percent of samples were used as input and remaining were divided to two parts and incubated with AIF monoclonal antibody or IgG overnight at $4{ }^{\circ} \mathrm{C}$. RNAs bound to specific proteins, were separated by Dynabeads protein $\mathrm{G}$ beads (Invitrogen) and extracted by TRIzol. SNHG15 RNA levels were quantified by qRT-PCR using 3 pairs of SNHG15 primers. MALAT-1, U6, GAPDH and HPRT were used as negative controls and the data were presented to the value obtained from IgG.

\section{Immunofluorescence}

A density of $75 \times 10^{3}$ LoVo cells were seeded on coverslips placed in the bottom of each well in 12 well plates. $48 \mathrm{~h}$ after inhibition by siRNAs, cells were fixed in $4 \%$ PFA solution for $30 \mathrm{~min}$ at RT and then washed with washing buffer. Non-specific binding was blocked using block solution containing 10\% FBS. Cells were incubated in anti-AIF prepared in block solution (1:250; sc-13,116; Santa Cruz) for $30 \mathrm{~min}$ at RT. Then washed two times with washing buffer, followed by $30 \mathrm{~min}$ incubation in secondary Alexa fluor 488 donkey anti-mouse IgG (A-21202, Thermo Fisher). Coverslips were mounted on slides using mounting solution. All images were captured using LSM 800 (Zeiss, Jena, Germany) inverted confocal microscope equipped with a 63x Plan-Apochromat objective (NA1.4 oil).

\section{ROS assay}

LoVo cells were transfected with combination of two si-SNHG15 and si-control. After $48 \mathrm{~h}$, cells were collected and cell lysates were prepared. Cellular ROS level were measured by OxiSelect in vitro ROS/RNS assay kit (Cell biolabs) according to the manufacturer's instructions, using fluorescence plate reader. Results are shown as change in relative fluorescence unit (RFU).

\section{Chemotherapy sensitivity assay}

$24 \mathrm{~h}$ after transfection of LoVo or HCT 116 cells, $5 \times 10^{3}$ cells were plated in each well of 96-plates. Plates were incubated for another $24 \mathrm{~h}$ and then treated with 0 to $50 \mu \mathrm{g} / \mathrm{mL}$ of 5 -FU (Sigma). Cells proliferation was determined using CellTiter96 Aqueous Non-Radioactive Cell Proliferation Assay (MTS) kit (Promega ${ }^{\circ}$ ) every $24 \mathrm{~h}$ for upto 3 days. Viability of the cells was determined by the following equation: (cells treated with 5-FU Abs/ Untreated cells Abs) $\times 100$.

\section{RNA sequencing}

LoVo cells were transfected with combination of two siRNA and control si-RNA. RNA was extracted by
Maxwell 16 LEV simply RNA kit (Promega) from three biological replicates and the quality of them, were assessed by High sensitivity RNA ScreenTape system (Agilent Technologies). Library preparation was performed with the TruSeq Stranded mRNA kit (Illumina). Libraries were then sequenced on an Illumina NextSeq (75 bp paired-end). Sequenced reads were aligned using bowtie2 (against hg19) and the differential gene expression analysis was carried out with DeSeq2. Biological knowledge extracted by using Ingenuty Pathway Analysis (QIAGEN Inc., https://www.qiagenbioinformatics.com/ products/ingeuity-pathway-analysis).

\section{Statistical analysis}

All data were analyzed using GraphPad Prism software (GraphPad Software, version 5.01, CA, USA). Two-tailed student's t-test was used to analyze normal distributed data and differences were considered significant at $p<0.05$.

\section{Results \\ SNHG15 is upregulated in colorectal cancer and is highly correlated with poor survival}

To characterize lncRNAs deregulated in CRC and correlated with survival, we profiled their expression in Tumor Cancer Genome Atlas (TCGA) cohort of 456 tumoral and 41 normal tissue samples. We found 14 lncRNAs as the most significantly deregulated transcripts (Fig. 1a, Additional file 3: Table S3), for which their upregulation was related to a significant decrease in survival of CRC patients (Table S3). Among them, we focused on SNHG15 due to its highly significant upregulation in tumors ( $p$ value $=7.5 \mathrm{e}-23$ ) and also the highest correlation with poor survival of patients $(p$ value $=$ 4e-5) (Fig. 1b). More investigations in this cohort of tumors containing different stages of CRC revealed that although there is a significant upregulation of SNHG15 expression in tumors versus normal samples, there is no obvious difference among CRC patients at various stages (Fig. 1c). These results suggest that SNHG15 upregulation is an early event in colorectal cancer promotion and its expression is maintained at high levels until last stage.

To confirm this observation, we obtained 36 fresh colorectal cancer tumors and their adjacent normal tissues immediately after surgery from Iranian CRC patients (Table 1). SNHG15 expression was examined by qRT-PCR and its upregulation was observed in tumoral samples (Fig. 1d, $p<0.001$ ). Moreover, we profiled SNHG15 expression in ten CRC cell lines (Caco-2, DLD-1, HCT 116, HT-29, LoVo, LS513, RKO, SW480, SW620 and T84) and found this lncRNA ubiquitously expressed in all tested CRC cell lines and with higher levels compared to the non-cancerous HDFa cell line (Fig. 1e). 


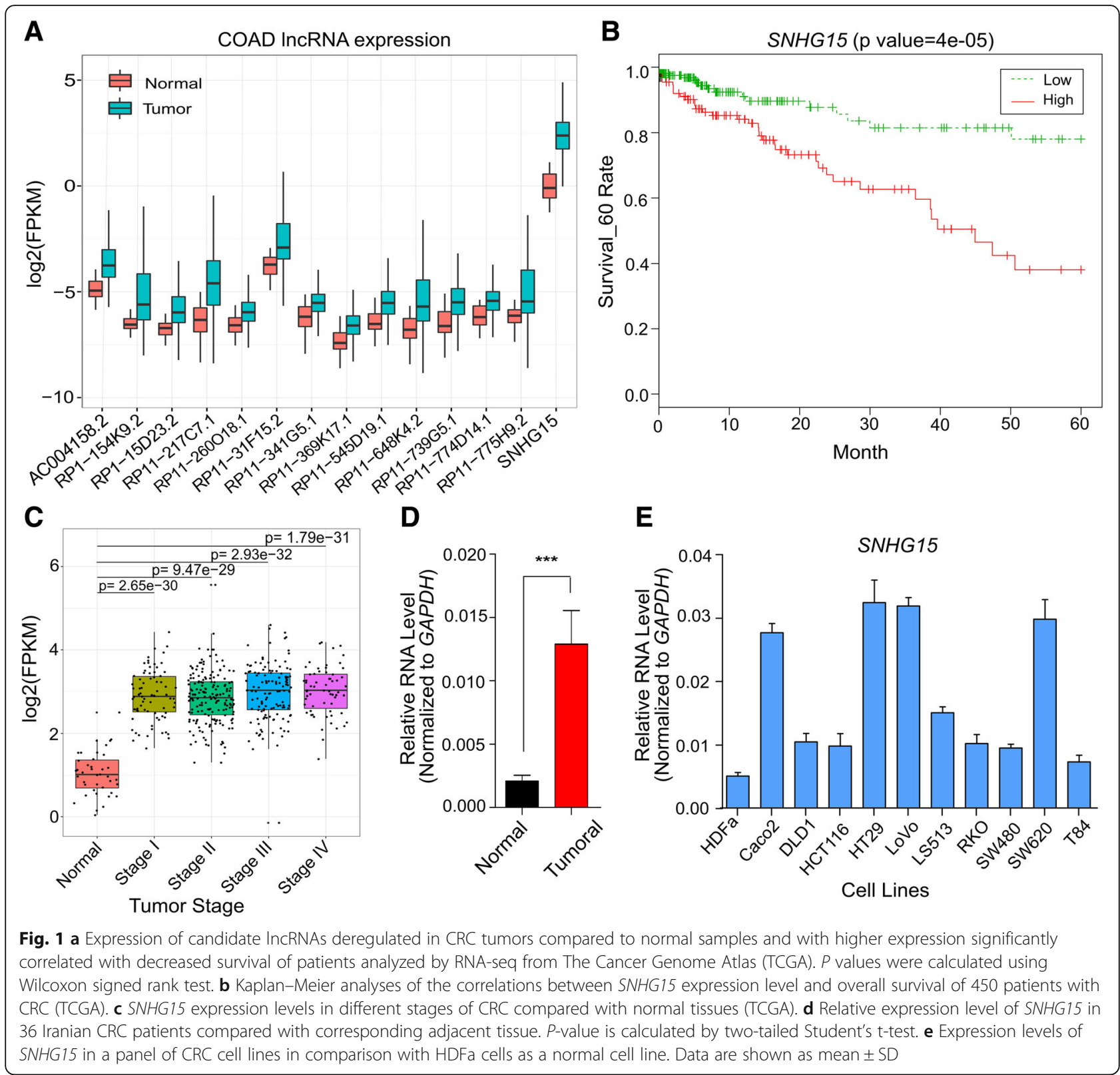

\section{SNHG15 expression is regulated in the cell cycle and transcriptionally controlled by MYC}

SNHG15 (small nucleolar RNA host gene 15) is located on chromosome 7 and composed of 5 exons. According to GENCODE V29 annotation, it can be spliced into different isoforms, although isoform 2 is the most abundant [18]. Interestingly, SNORA9 (small nucleolar RNA, H/ ACA box 9) is encoded in intron 2 of SNHG15 (Fig. 2a). SNORA9 also named ACA9 is a member of H/ACA pseudouridylation guide RNA machinery, which contributes to pseudouridine synthesis in snRNAs and rRNAs [19]. Coding potential analysis revealed that SNHG15 sequence does not have ability to code for proteins (Fig. 2b). In agreement with this, polysome fractionation methods revealed that SNHG15 is not associated with polysomes (Additional file 4: Figure S1).

Previous studies revealed that there are two E-box (CACGTG) binding motifs for transcription factor MYC on the first exon and first intron of SNHG15 [20]. We therefore analyzed ChIP-seq data from ENCODE and confirmed that MYC is bound to these boxes in different cancerous cell lines (Fig. 2c).

In order to investigate the transcriptional regulation of SNHG15 by MYC, we analyzed colorectal adenocarcinoma RNA-seq data from TCGA, finding that SNHG15 is significantly upregulated in the tumors with high level of $M Y C$ expression (Fig. 2d). In agreement with this observation, the depletion of $M Y C$ in LoVo CRC cell line 


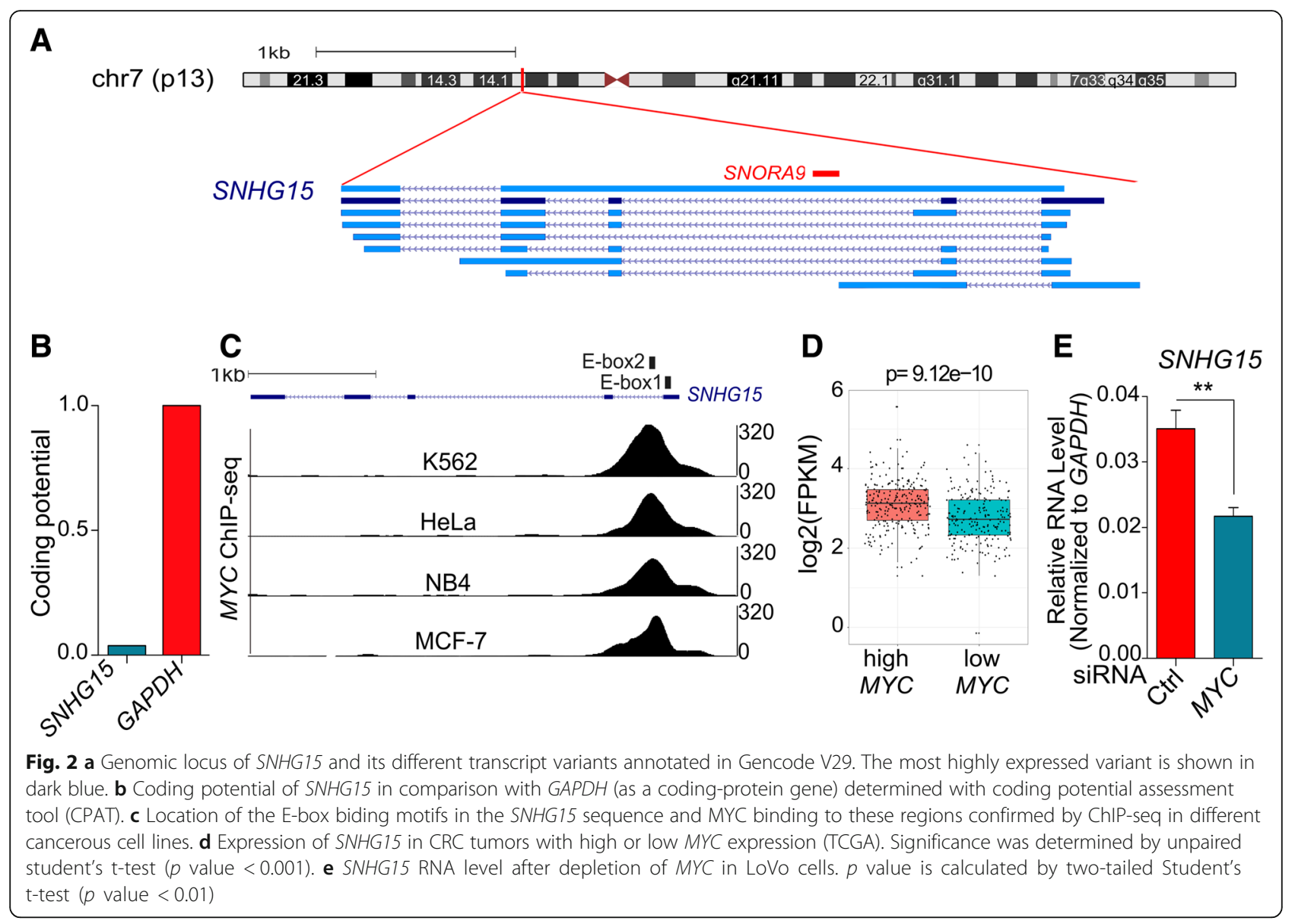

resulted in a significant decrease in the level of SNHG15 (Fig. 2e). These results indicate that SNHG15 transcription is controlled by MYC.

Since MYC is well known to regulate cell cycle, we investigated expression of SNHG15 during cell cycle. To do this, we obtained G1/S synchronized cells by double thymidine block procedure and collected the cells at different time points after block release. Results showed that SNHG15 expression is regulated during the cell cycle, with an increased expression of SNHG15 in G2/M phase (Additional file 5: Figure S2). Together, these data suggest that $S N H G 15$ is transcriptionally regulated by MYC in a cell-cycle dependent manner.

\section{SNHG15 deregulation has strong effects on proliferation,} invasion and tumor formation abilities of CRC cells

To investigate SNHG15 function in CRC, we designed two siRNAs to knock it down, and transfected LoVo and SW620 cells with each one of them individually or a combination of both. qRT-PCR analysis showed that $48 \mathrm{~h}$ after transfection, SNHG15 transcript was significantly reduced, while the expression level of SNORA9, which is located in one of its introns, was not changed (Fig. 3a and c). These results confirmed that the designed siRNAs target SNHG15 exons after splicing, leaving intact SNORA9, and allowing studying SNHG15 function independently of SNORA9. Further investigation showed that the knockdown of SNHG15 significantly inhibited cell proliferation (Fig. $3 \mathrm{~b}$ and $\mathrm{d}$ ) and colony formation capacity of these cells (Fig. 3e-f). However, downregulation of SNHG15 did not significantly influence the cell cycle profile or the percentage of apoptotic cells (Fig. 3g-h). On the other hand, the invasion capacity of the cells was significantly decreased after SNHG15 inhibition, as quantified by transwell assays (Fig. $3 \mathrm{i}-\mathrm{j}$ ).

We subsequently investigated the effects of SNHG15 overexpression on cell growth, invasion and tumor formation capacity. To do so, SNHG15 cDNA sequence ( $837 \mathrm{bp}$ ) was cloned and expressed transiently in HCT 116 and SW480 cells, which express SNHG15 at lower levels compared to LoVo and SW620 cells. qRT-PCR analysis indicated a significant increase in SNHG15 RNA levels relative to the control cells transfected with the empty vector (Fig. 4a and d). MTS assay showed that the enforced expression of SNHG15 led to a significant increase in cell proliferation (Fig. $4 \mathrm{~b}$ and e). Colony formation assay also 

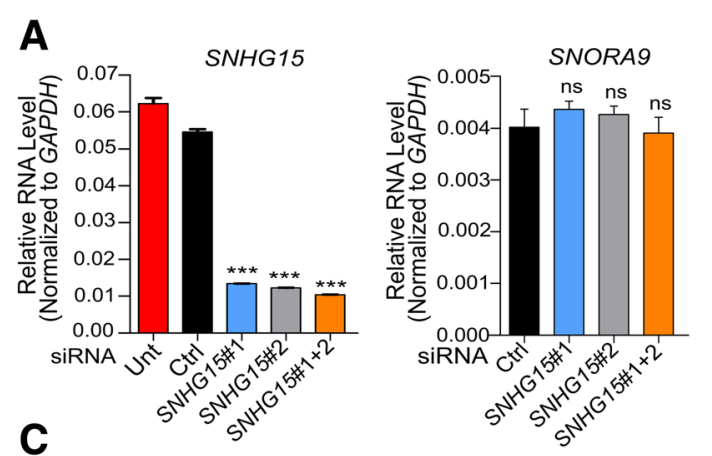

B
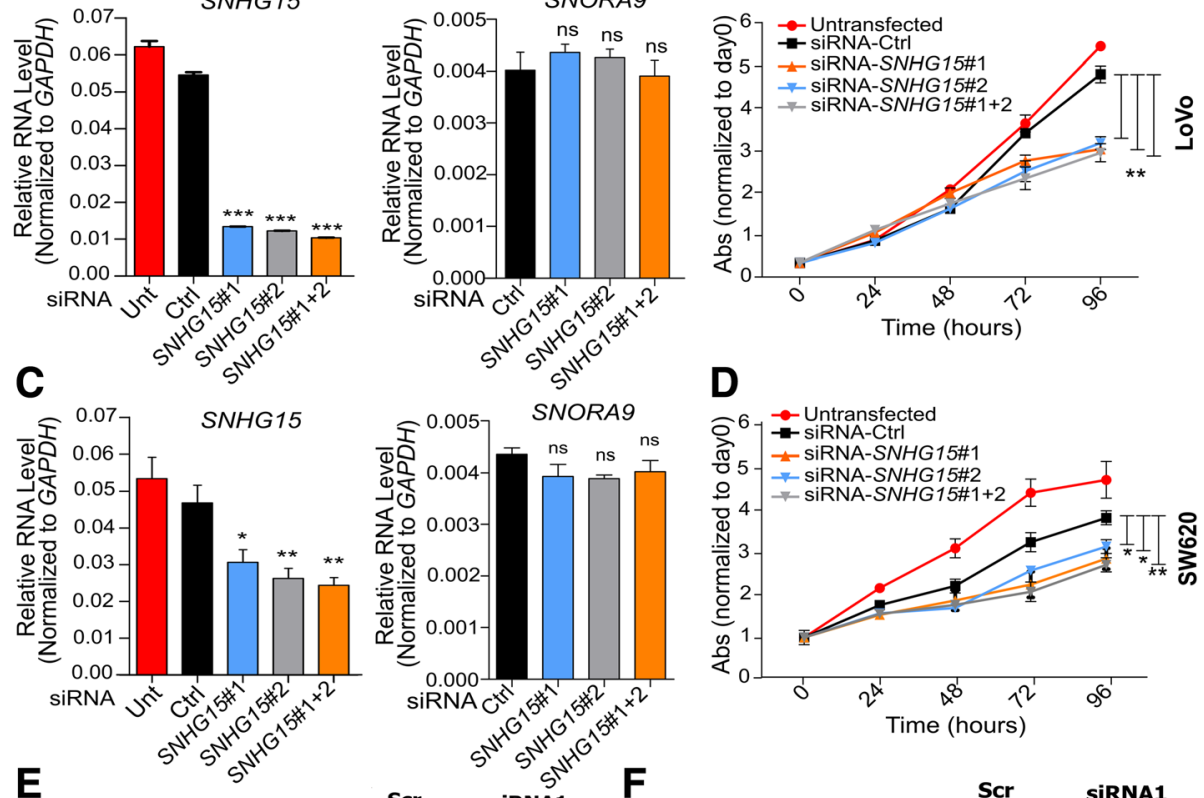

D

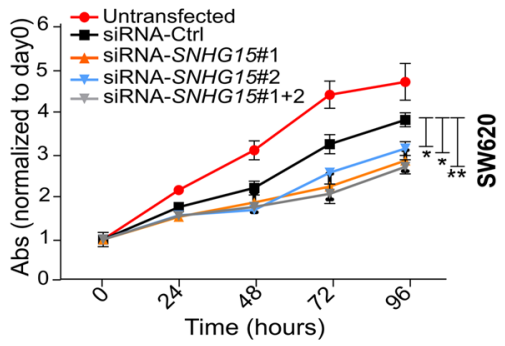

$\mathbf{E}$
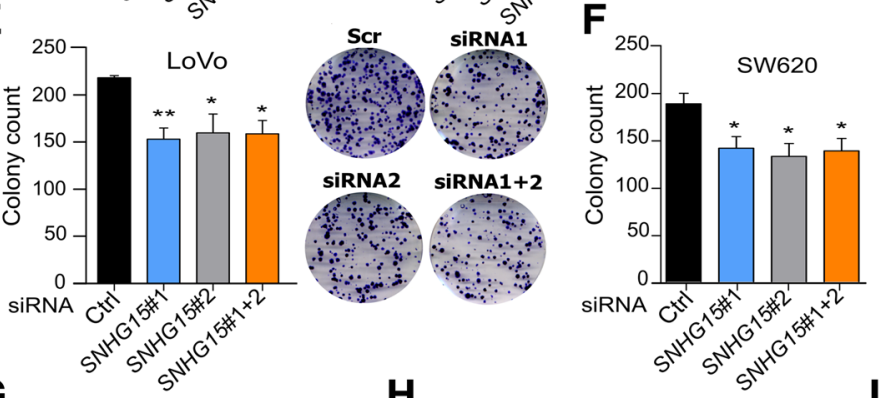

G

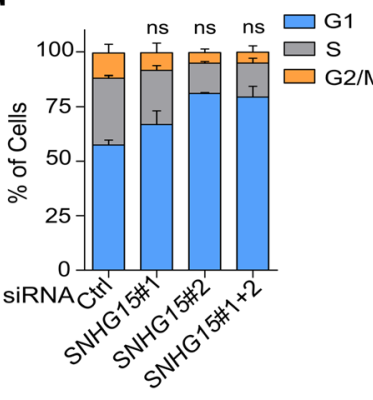

H $\quad$ ns ns ns $\square$ Apoptotic
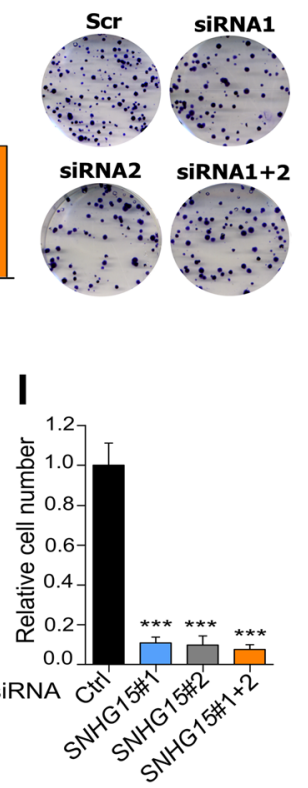

$\mathbf{J}$
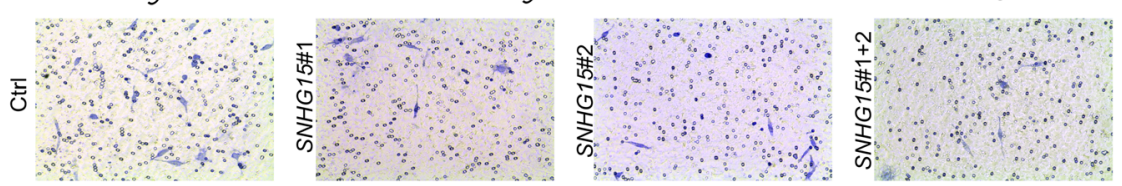

Fig. 3 a SNHG15 and SNORA9 RNA level after knockdown with the two siRNAs separately or in combination in LoVo cells. b Cell proliferation measured by MTS assay after inhibition of SNHG15 in LoVo cells. c SNHG15 and SNORA9 expression levels in SW620 cells after inhibition of SNHG15 with siRNAs. d Proliferation capacity of SW620 after SNHG15 knockdown. e The results of colony formation assay performed quantified after 10 days of inhibition in LoVo cell line and (f) in SW620 cell line. $\mathbf{g}$ Cell-cycle phase distribution of LoVo cells determined by propidium iodide-staining (h) Percentage of apoptotic LoVo cells after staining with annexin V and 7-AAD (i) Number of LoVo cells invading through the membrane under the indicated conditions in the transwell assay. $\mathbf{j}$ Invading LoVo cells stained on transwell chambers after $48 \mathrm{~h}$ in each condition. The statistical analysis is performed by two-tailed Student's t-test and graphs shows mean \pm SEM of values $\left({ }^{*} p<0.05\right.$, $\left.{ }^{* *} p<0.01,{ }^{* * *} p<0.001\right)$ 

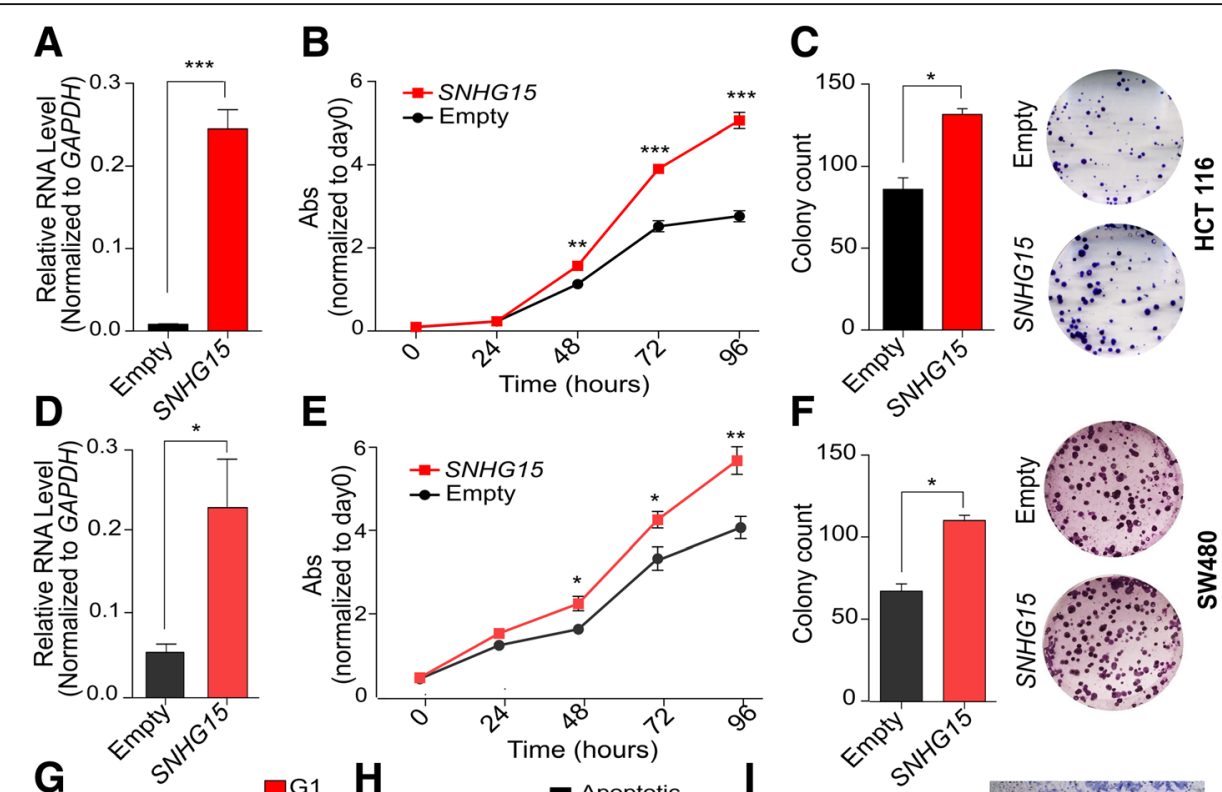

$\mathbf{E}$

$\mathbf{F}$
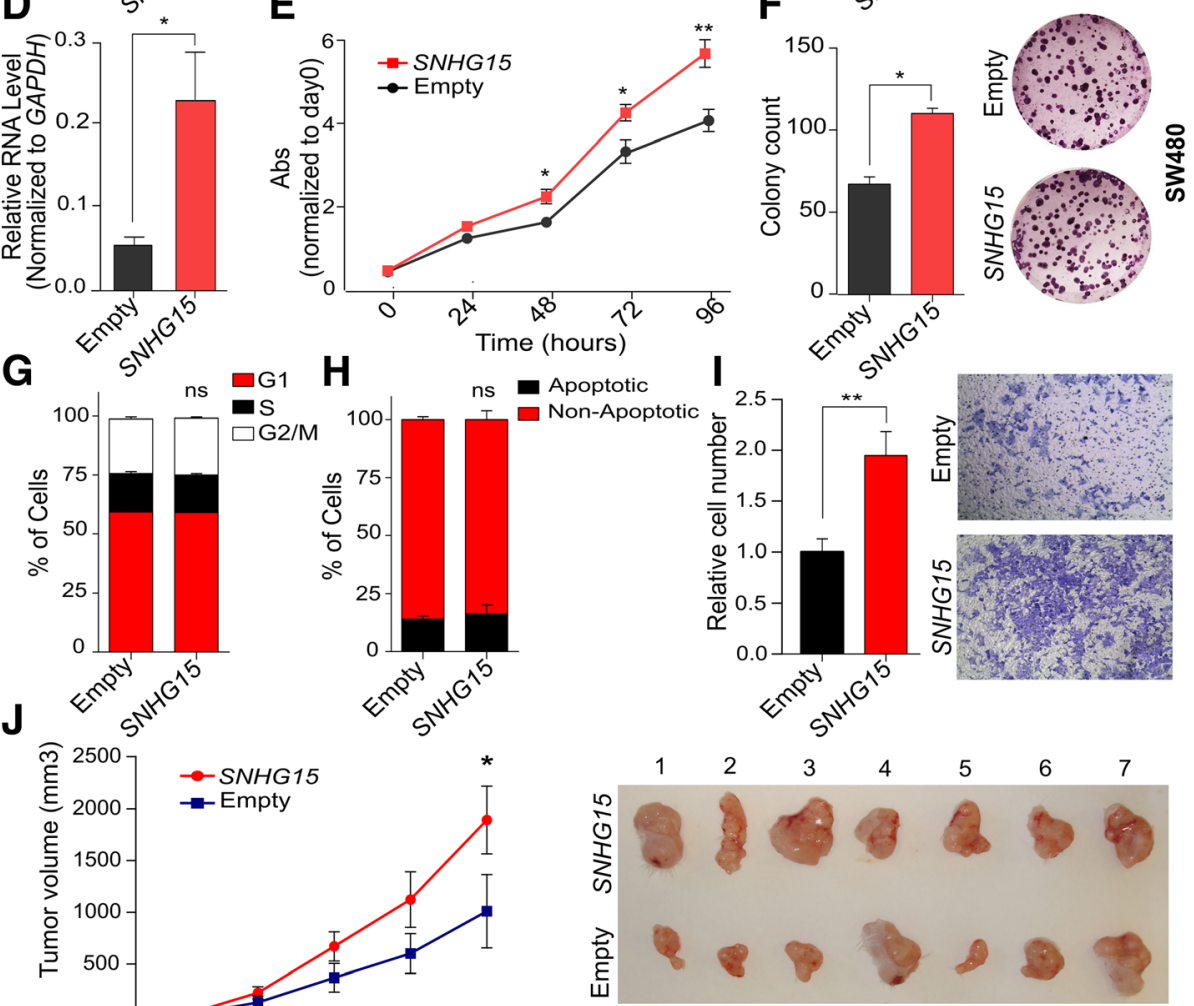

Fig. 4 a Level of SNHG15 after overexpression in HCT116 cells determined by qRT-PCR (b) Change in proliferation ability of HCT116 cells after overexpression of SNHG15 in comparison with control. c Colony formation ability in overexpressing cells comparing to control cells. d SNHG15 RNA level after Transfection SW480 cells with SNHG15-vector via Empty vector. e Change in cell proliferation ability after SNHG15 overexpression in SW480 cell line. f Results of colony formation assay after overexpressing SNHG15 in SW480 cells. $\mathbf{g}$ Cell cycle analysis in HCT 116 cells after overexpression of SNHG15 using propidium iodide staining. $\mathbf{h}$ Percentage of apoptotic HCT 116 cells determined by annexin V and 7-AAD staining. $\mathbf{i}$ Invasion ability of HCT116 cells after overexpression of SNHG15. $\mathbf{j}$ Tumor formation in immunodeficient mice of the same cell lines $(n=$ 7). $P$ value is calculated by two-tailed Student's t-test and graphs shows mean \pm SEM of values $\left({ }^{*} p<0.05,{ }^{* *} p<0.01,{ }^{* *} p<0.001\right)$

indicated that SNHG15-overexpressing cells not only could form more colonies but also of larger size (Fig. $4 \mathrm{c}$ and f). Consistently with the phenotype observed upon depletion, SNHG15 overexpression did not influence cell cycle or apoptosis in HCT 116 cells (Fig. $4 \mathrm{~g}-\mathrm{h})$. In addition, the overexpression of SNHG15 in HCT 116 cells increased their invasion capacity (Fig. 4i).

To further explore the role of SNHG15 in the tumorigenicity of CRC cells, SNHG15-overexpressing and control HCT 116 cells were injected into immunodeficient mice, and the tumor size was measured every 4 days. As shown in Fig. 4j, tumors grew faster in cells overexpressed SNHG15, and larger and heavier tumors were formed by these cells after 4 weeks.

In order to confirm our results and exclude possible off target effects of the siRNAs, we knocked-out SNHG15 by CRISPR-Cas9 system in LoVo cells. Two guide RNAs (gRNAs) were designed to delete a region of SNHG15 of around $1400 \mathrm{bp}$ without affecting SNORA9 sequence 


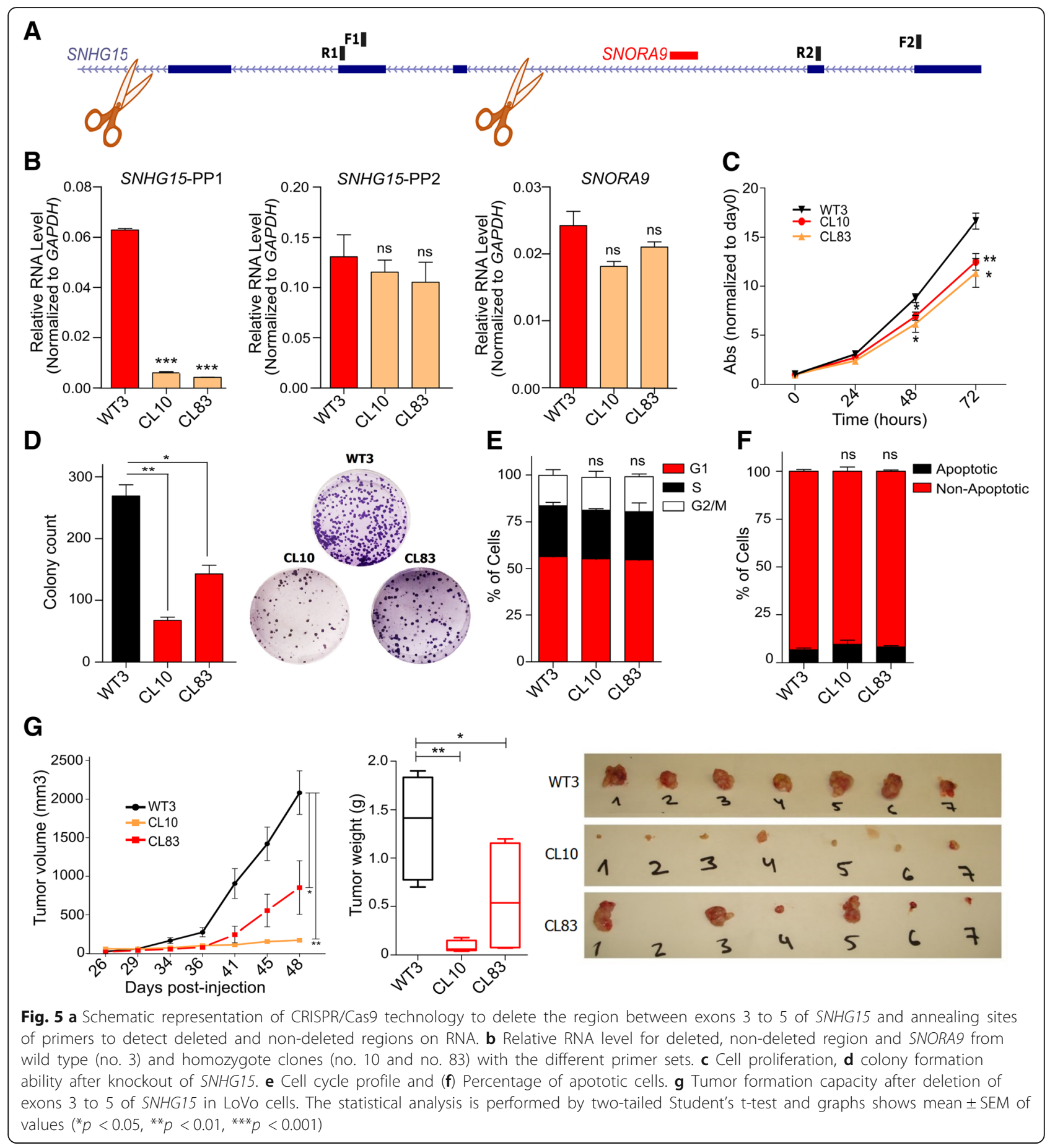

(Fig. 5a). Several clones were obtained with homozygote deletion. After screening of the clones, we chose two independent clones with deletion in the aimed region confirmed by qRT-PCR with two pairs of primer designed specifically for deleted and non-deleted region. Of note, they no changes in SNORA9 expression were observed (Fig. 5b). The experimental characterization of these two clones showed their low proliferation and colony formation capacity (Fig. 5c, d), while didn't show significant changes in cell cycle profile and percentage of apoptotic cells (Fig. 5e-f). Moreover, xenograft mice model experiments confirmed our previous data and revealed that the tumors formed by knock-out cells were smaller and lighter 
than those formed by the wild type cells (Fig. 5g). Together, these results suggest that SNHG15 promotes the oncogenic capacity of CRC cells.

\section{SNHG15 depletion in CRC cells affects the expression of genes with roles in cell proliferation, migration and survival}

To determine the biological processes and pathways regulated by $S N H G 15$, a gene expression analysis by RNA-seq was performed in LoVo cells after transfection with combination of two siRNAs or a negative control siRNA. Our results revealed an elevated number of genes significantly deregulated upon SNHG15 depletion (Fig. 6a - Additional file 6: Table S4). Among 766 genes with a significant change of expression (FDR $<0.05), 372$ genes were upregulated and 394 genes were downregulated. In order to obtain more information about SNHG15 function, Ingenuity Pathway Analysis (IPA) was performed, showing that the genes affected by SNHG15 knockdown are preferentially associated to cancer as well as cell death and survival (Fig. 6b). Interestingly, more detailed canonical pathway analysis showed that these genes contribute to some important molecular pathways and mechanisms of cancer, including polyamine regulation in colon cancer, GADD45 signaling, chromosomal replication during cell cycle and role of CHK protein in cell cycle checkpoint control (Fig. 6c). We chose 20 candidates among the genes detected by the RNA-seq and pathway analyses to validate the changes in their expression caused by SNHG15 depletion. Results showed that CTGF, GADD45A, GADD45B, HAS2, LAMC3, NRAS, BAG3, ERBB3, MYC and CASP3 were deregulated after $S N H G 15$ inhibition with each individual siRNA or by the combination of them (Fig. 6c), confirming the effect of SNHG15 in the regulation of these relevant genes.

\section{SNHG15 interacts with AIF in the cytoplasm and contributes to the resistance to stress}

The gene expression analysis performed reflected the physiological changes caused by SNHG15 downregulation in CRC cells in terms of proliferation and tumorigenicity. However the analysis did not provide insights into the mechanism by which SNHG15 affects the biology of the tumor cells. To investigate the mechanism by which SNHG15 regulates CRC proliferation, we first set to determine its subcellular localization. Nuclear-cytoplasmic fractionation in LoVo cells showed that this lncRNA is mainly cytoplasmic (Fig. 7a). We hypothesized that SNHG15 interacts with cytoplasmic proteins to carry out its functions, so we focused on identifying specific physical interactions with SNHG15. To that end, we performed RNA pull-down using in vitro transcribed SNHG15 RNA or an unrelated RNA of similar length (murine linc-p21) as control. The RNAs were incubated with cytoplasmic extract of LoVo cells and mass spectrometry (MS) was performed on the differential band found on the retained proteins (Fig. 7b, upper panel). Apoptosis Induced Factor (AIF) was identified as a protein bound to SNHG15 with 8 unique peptides but absent in the control RNA pull-down. AIF is a bifunctional protein that exhibits distinct roles based on its subcellular localization. After translation in the cytosol AIF is transported to the mitochondria, where it acts as an NADH oxidase to generate $\mathrm{O}_{2}{ }^{-}$and subsequently $\mathrm{H}_{2} \mathrm{O}_{2}$ [21]. In consequence, AIF has an effect on reactive oxygen species (ROS) levels with a strong impact in various cellular stress and survival pathways $[22,23]$. On the other hand, upon apoptotic stimulus AIF can be cleaved and translocated to the nucleus, where it binds to DNA and promotes chromatin condensation and DNA fragmentation, which are necessary for the apoptosis program [24]. Interestingly, the molecular weight of the isoform that we found as interacting with SNHG15 is around $67 \mathrm{kDa}$ (full length protein), indicating that SNHG15 binds to the precursor AIF.

The interaction between SNHG15 and AIF was further validated by western blot using specific antibody against AIF (Fig. 7b). Moreover, it was confirmed by RNA immunoprecipitation (RIP) with an antibody able to specifically immunoprecipitate the endogenous AIF (Fig. 7c). To further investigate the functional relationship between SNHG15 and AIF, immunofluorescence studies were performed showing that inhibition of SNHG15 did not change AIF subcellular localization from cytoplasm to nucleus (Fig. 7d), suggesting that SNHG15 is not implicated in the pro-apoptotic function of AIF.

Based on these observations and the phenotype observed in the cells upon SNHG15 inhibiton, we hypothesized that SNHG15 binding to AIF does not influence AIF role in apoptosis, but may affect the other mechanism in which the protein has been involved, i.e. respiratory chain and stress response [22, 23]. To test this hypothesis, we measured ROS levels in SNHG15-depleted cells in comparison to controls. As shown in Fig. 7e, after depletion of SNHG15, ROS levels resulted in a significant reduction. Since enhancement of ROS is known to prevent cellular toxicity by neutralizing chemical stresses [22, 23], we examined whether the expression of SNHG15 had an influence on survival of CRC cells after treatment with 5-FU as chemical stress. To do this, we depleted or overexpressed SNHG15 in CRC cells (LoVo or HCT 116) and exposed them to different concentrations of 5 -FU (0 to $50 \mu \mathrm{g} / \mathrm{mL}$ ). After $48 \mathrm{~h}$ of drug treatment, the results on proliferation assay showed that SNHG15 levels had a significant influence on the response of CRC to $5-\mathrm{FU}$ at $8 \mu \mathrm{g} / \mathrm{mL}$. At this concentration, SNHG15-depleted cells were more sensitive to 5-FU and their viability was lower compared to control cells. On the other hand, SNHG15-overexpressing 


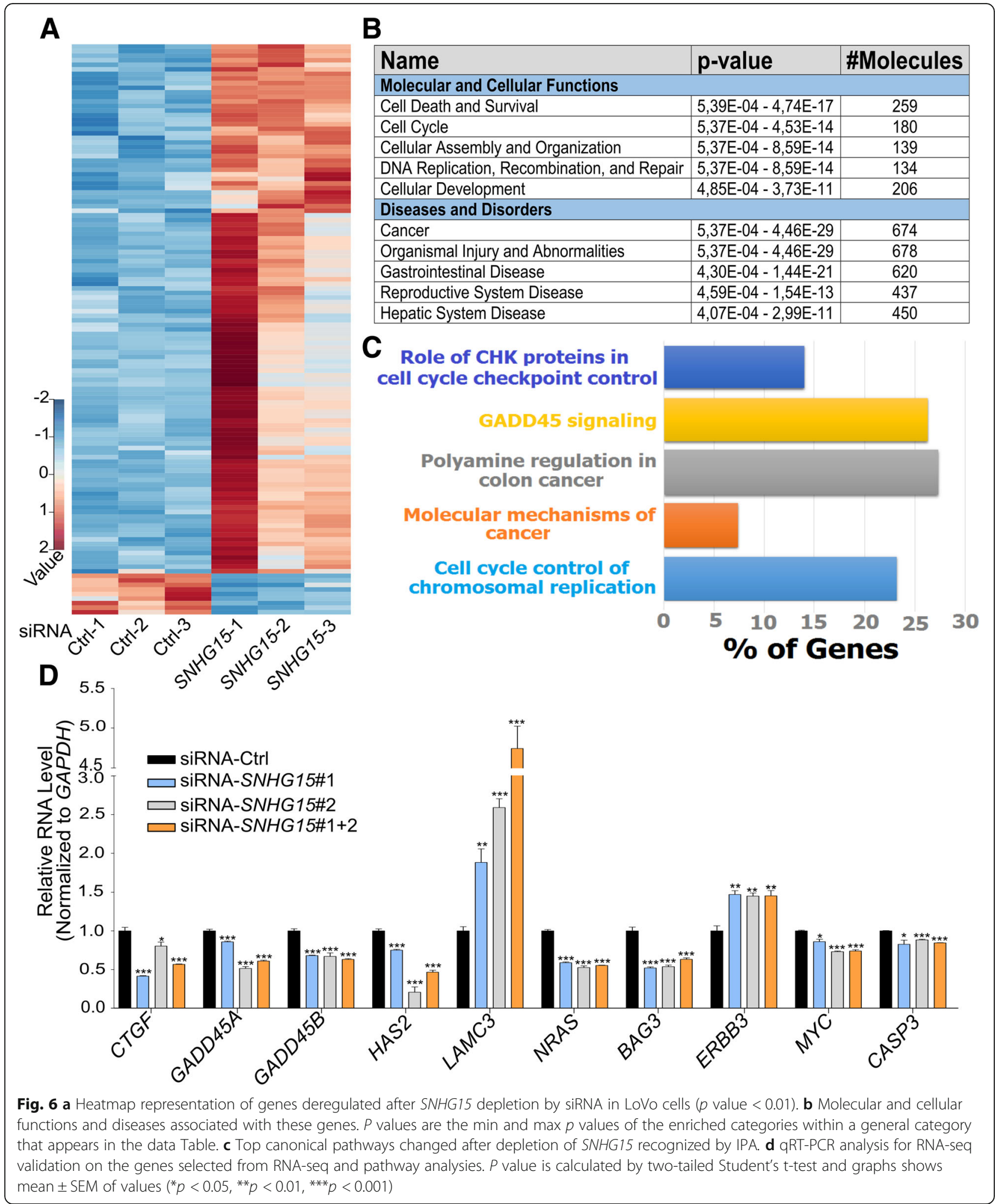

cells showed more resistance and higher survival to the drug treatment than control cells (Fig. 7f). These results suggest that the increased levels of SNHG15 are related with the capacity of CRC cells to cope with the cytotoxic stress caused by 5 -FU, which could be mediated by its interaction with AIF. In agreement with these findings, 

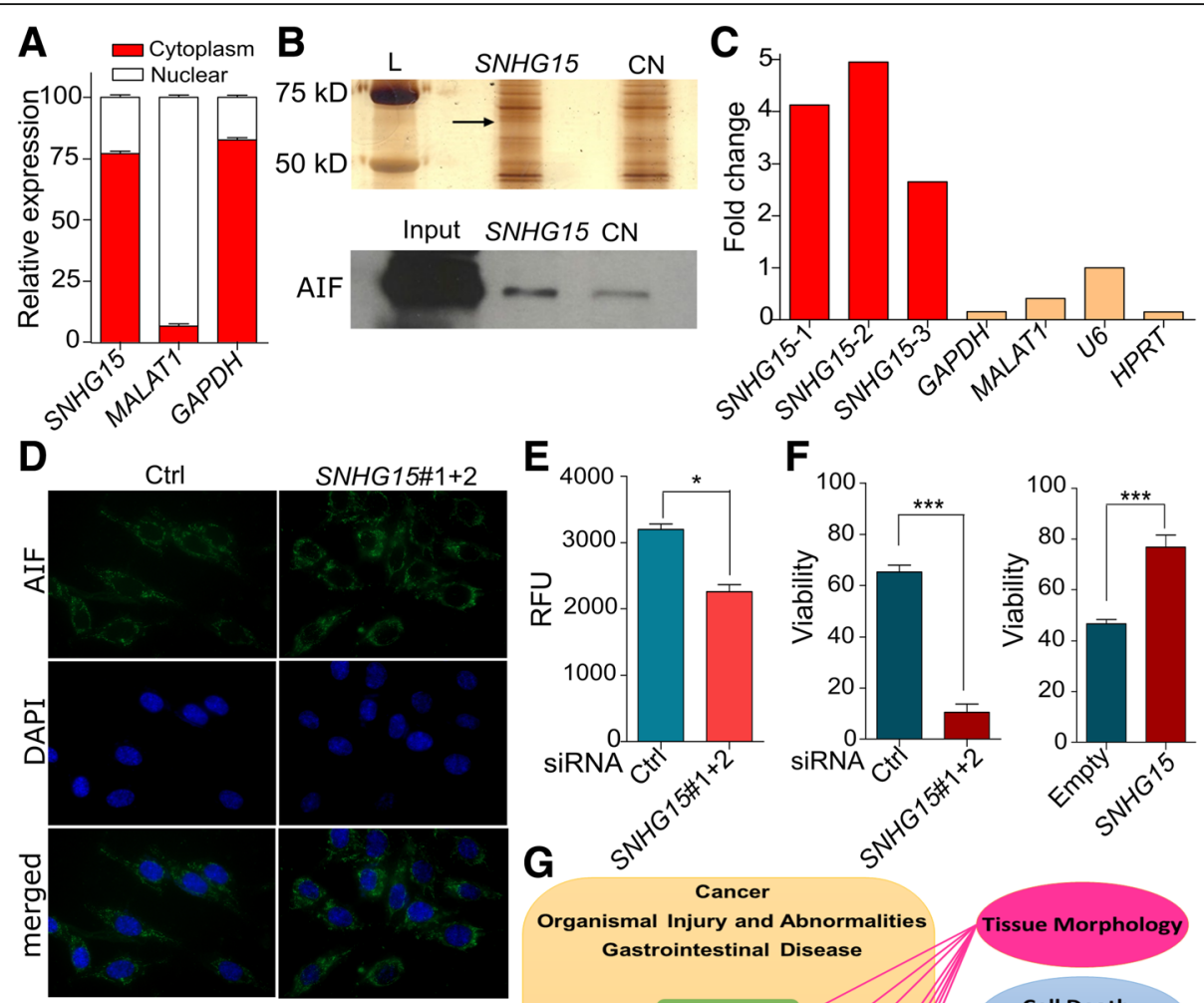

$E_{4000} \mathbf{F}$
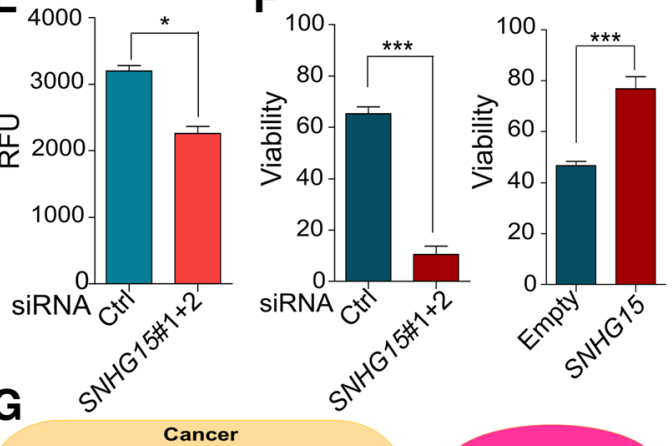

Organismal Injury and Abnormalities Gastrointestinal Disease

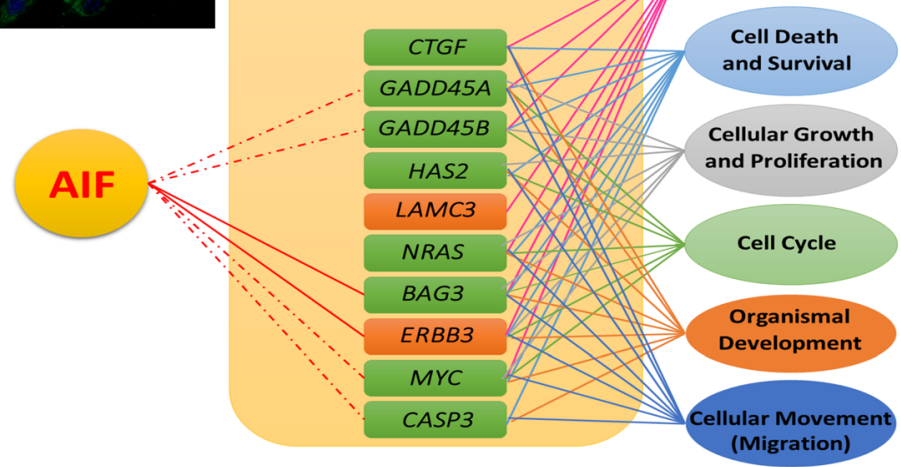

Fig. 7 a RNA levels of SNHG15 and control RNAs in nuclear and cytoplasmic fractions measured by qRT-PCR. The statistical analysis is performed by two-tailed Student's t-test $\mathbf{b}$ Top: Silver stained gel with the proteins retained in the RNA pull-down experiment by SNHG15 and linc-p21 as negative control (CN), the differential band analyzed by mass spectrometry is indicated by an arrowhead; bottom: detection of the AlF protein by western blot in a replicate of the RNA pull-down experiment. c RNA immunoprecipitation using AIF monoclonal antibody and followed by qRTPCR using three different primer pairs for SNHG15, and MALAT-1, U6, GAPDH and HPRT as negative controls. d AIF localization after SNHG15 inhibition using immunofluorescence antibody. Nuclei were stained with DAPI. e ROS levels of in LoVo cells transfected with the indicate siRNAs ( $p$ value< 0.05 ). $\mathbf{f}$ Cell viability determined by MTS of CRC cells (LoVo and HCT 116) after depletion or overexpression of SNHG15 treated with $8 \mu \mathrm{g} / \mathrm{mL}$ for $48 \mathrm{~h}$ ( $p$ value< 0.001 ). $\mathbf{g}$ Connection between AIF and the genes validated with most important pathway recognized. The statistical analysis is performed by two-tailed Student's t-test and graphs shows mean \pm SEM of values

pathway analysis on the genes affected by SNHG15 knockdown revealed that many of them are functionally related to AIF. Moreover, the role of this group of genes in many important cellular mechanisms such as tissue morphology, cell death and survival, cellular growth and proliferation, cell cycle, organismal development and cellular movement (migration) was confirmed. It was also revealed that these genes contributed in some disorder like cancer, gastrointestinal disease, organismal injury and abnormalities (Fig. 7g).

\section{Discussion}

Since colorectal cancer is the third most common human malignancy worldwide [13], many researchers have focused on the characterization of CRC-related lncRNAs as new biomarkers for diagnosis or targeted therapy of this disease. Some of these important lncRNAs include CCAT1, H19, HOTAIR, MALAT1, UCA1 and PTENP1 $[14,25]$. In this study, we searched for IncRNAs strongly associated with poor prognosis of CRC. SNHG15 was identified as an oncogenic lncRNA whose upregulation 
was related to poor survival of CRC patients. Interestingly, the classification of colorectal adenocarcinoma TCGA samples relative to $M Y C$ expression showed that SNHG15 is upregulated in the samples with high levels of $M Y C$ expression. More investigation confirmed that MYC has two binding sites (E-box) on SNHG15 sequence and bound them in different cancerous cell lines. Furthermore, its inhibition by siRNA, led to decrease SNHG15 level in CRC cell line and confirmed that SNHG15 is transcriptionally regulated by MYC. On the other hand, RNA-seq results showed significant reduction of MYC transcript after depletion of SNHG15. These finding suggest a feedback loop between SNHG15 and MYC expression that introduce SNHG15 as an additional component of the pro-proliferative network activated by this oncogenic transcription factor. Consistently with this notion, the depletion of SNHG15 by different experimental methods leads to decreased cell proliferation, while its enforced expression promotes cell proliferation and clonogenicity.

Long non-coding RNAs have been involved in a variety of mechanisms that can take place in different cellular compartments. Although some studies have addressed the role of SNHG15 in the nucleus [18], in LoVo cells SNHG15 is mainly localized in the cytoplasm, suggesting that it has a role in this cellular compartment. To elucidate the role of SNHG15, we searched for proteins with specific physical interactions with SNHG15, identifying AIF as associated with SNHG15. AIF mRNA is translated in the cytoplasm into a 613-amino acid precursor (67 $\mathrm{kDa})$ that is transported to mitochondria via mitochondrial localization signal (MLS). After being imported into the intermembrane space, the first 34 amino acids are removed and the $62 \mathrm{kDa}$ mature AIF (AIFmit) is generated to contribute to the respiratory chain as an NADH oxidase [21, 26]. If cells receive an apoptotic stimulus, a different cleavage occurs in AIFmit by calpain or cathepsin, and a $57 \mathrm{kDa}$ AIF is formed to induce DNA condensation and DNA fragmentation in the nucleus [27-29].

It has been shown that AIF maintains the transformed state of CRC cells via its NADH oxidase activity and cells show more apoptosis sensitivity as a result of AIF knockout and decreases in ROS level. In other words, AIF helps to neutralize chemical stress, and increased protein level of AIF leads to enhancement of ROS to prevent cellular toxicity [22, 23]. Interestingly, we did not observe significant changes in the number of apoptotic cells after dysregulation of SNHG15. In addition, inhibition of SNHG15 did not induce translocation of AIF into nucleus after $48 \mathrm{~h}$. These data suggest that under these experimental conditions, i.e. in the absence of apoptotic stimulus, SNHG15 mainly affects the oxidation-related function of AIF. Given the full-length size of the AIF protein interacting with $S N N H 15$, and the subcellular localization of the lncRNA, we speculate that SNHG15 could interact with AIF upon the protein translation, coupling it to its correct translocation to the mitochondria. Interestingly, many studies have demonstrated that several members of the HSP70 family could bind to AIF and neutralize this protein [30]. Gurbuxani et al. showed that fragment between amino acids 150 to 228 of AIF is necessary for binding to HSP70 and this interaction block AIF nuclear localization [31]. As this fragment exists in both isoform of AIF, this process may occur for mitochondrial localization, so it is possible that binding SNHG15 to AIF could prevent AIF neutralization by HSP70 family and help it to translocate to intermembrane space of mitochondria for contributing in respiratory chain activities and stress response. In agreement with our observations, previous studies have shown that SNHG15 contribute to the molecular mechanism of cellular stress response. This lncRNA is a short-lived lncRNA $(\mathrm{t} 1 / 2<4 \mathrm{~h})$ and its expression level is increased significantly after $24 \mathrm{~h}$ cycloheximide used as a stressor, when its half-life was increased from 3.4 to more than $24 \mathrm{~h}$ after this treatment [32]. We showed that after depletion of SNHG15, ROS levels are significantly decreased, and drug sensitivity experiments showed that inhibition of SNHG15 could sensitize CRC cells to 5-FU, which is a basic chemotherapeutic drug for CRC. Based on these results, we propose that the interaction between AIF and SNHG15 may be help to incorporate this protein in ROS formation pathway.

Gene expression analysis after depletion of SNHG15 revealed significant deregulation of multiple genes including CTGF, GADD45A, GADD45B, HAS2, LAMC3, NRAS, BAG3, ERBB3, MYC and CASP3. Most of these genes are known to play an important role in CRC tumor development and response to treatment. For example, CTGF decreases cell apoptosis and enhances CRC chemoresistance to 5-FU [33]. The inhibition of GADD45A leads to decrease in DNA repair and sensitize cells to ultraviolet-irradiation or cisplatin [34], while high level of its expression, turns CRC cells resistant to treatment with oxidative stress-inducing compounds [35]. GADD45B is significantly upregulated in CRC, and high levels of $G A D D 45 B$ expression are related to poor survival of patients [36]. Similarly, HAS2 [37, 38], NRAS $[39,40]$ and $B A G 3$ [41-43] have well-established roles in CRC carcinogenesis and response to chemotherapy. Therefore, the gene expression changes linked to the loss of SNHG15 are affecting central oncogenic pathways, including the response to chemotherapy and drug response, which is directly related of AIF function. However we cannot exclude that SNHG15 has additional functions in the cell. For instance, SNHG15 has been reported to control Slug stability in the nucleus [18] or regulate the levels of certain microRNAs [44-46]. It 
remains to be shown if the combination of other mechanisms with the AIF-dependent here described confers SNHG15 its full pro-oncogenic activity.

Beyond CRC, the dysregulation and oncogenic role of SNHG15 has been indicated in various types of cancer, including gastric [47] and hepatocellular carcinoma [48], osteosarcoma [44], as well as pancreatic [49] and breast cancers [46]. Our study, together with this body of work, including a recent study relating this lncRNA with increased liver metastasis of CRC tumors [50], indicate that SNHG15 possesses a broad oncogenic activity, and suggests that the development of tools to target the lncRNA could have therapeutic value across multiple cancer types.

\section{Conclusion}

Our results describe a role for the MYC-regulated SNHG15 locus in colorectal cancer, role dependent on the lncRNA encoded by this bifunctional gene. The lncRNA SNHG15 is able to promote colon cancer and mediating drug resistance, suggesting its potential as prognostic marker and target for RNA-based therapies.

\section{Additional files}

Additional file 1: Table S1. Primers used for qRT-PCR. (DOCX $12 \mathrm{~kb}$ )

Additional file 2: Table S2. Guide RNAs used for CRISPR-Cas9 editing. (DOCX $11 \mathrm{~kb}$ )

Additional file 3: Table S3. The most significantly deregulated IncRNAs with high expression correlated with low survival of patients. (DOCX $13 \mathrm{~kb}$ )

Additional file 4: Figure S1. Association possibility of SNHG15 to polysomes, GAPDH expression was evaluated as a positive control. (PNG $1830 \mathrm{~kb}$ )

Additional file 5: Figure S2. (A) Cell cycle analysis of CRC cells after synchronization with double thymidine block procedure. (B) SNHG15 expression level of synchronized cells after each time point. Graphs shows mean \pm SEM of values. (PNG $604 \mathrm{~kb}$ )

Additional file 6: Table S4. RNA seq analysis of LoVo cells after SNHG15 depletion.(XLSX $163 \mathrm{~kb})$

\footnotetext{
Abbreviations

5-FU: Fluorouracil; AIF: Apoptosis Induced Factor; ATCC: American Type Culture Collection; BAG3: BCL2 Associated Athanogene 3; CASP3: Caspase 3; CCAT1: Colon Cancer Associated Transcript 1; ChIP: Chromatin immunoprecipitation; CHX: Cycloheximide; CL: Clone; CRC: Colorectal cancer; CRISPR: clustered regularly interspaced short palindromic repeats; CTGF: Connective Tissue Growth Factor; Ctrl: Control; DAPI: 4,,6-diamidino-2phenylindole; DMEM: Dulbecco's modified Eagle's medium; EDTA: Ethylenediaminetetraacetic acid; ERBB3: Erb-B2 Receptor Tyrosine Kinase 3; FBS: Fetal bovine serum; FDR: False Discovery Rate; GADD45A: Growth Arrest and DNA Damage Inducible Alpha; GADD45B: Growth Arrest and DNA Damage Inducible Beta; GAPDH: Glyceraldehyde 3-phosphate dehydrogenase;

GENCODE: Encyclopedia of DNA Elements; GFP: Green Fluorescent Protein; gRNAs: guide RNAs; HAS2: Hyaluronan Synthase 2; HOTAIR: HOX Transcript Antisense RNA; HPRT: Hypoxanthine Phosphoribosyltransferase; IPA: Ingenuty Pathway Analysis; LAMC3: Laminin Subunit Gamma 3; IncRNA: Long Noncoding RNA; MALAT1: Metastasis associated lung adenocarcinoma transcript 1; miRNAs: microRNA; MLS: Mitochondrial Localization Signal; MS: Mass Spectrometry; NC: Negative Control; ncRNAs: non-coding RNAs; PBS: Phosphate Buffered Saline; PFA: Paraformaldehyde; piRNAs: Piwi-
}

interacting RNA; PTENP1: Phosphatase and Tensin Homolog Pseudogene 1; qRT-PCR: Quantitative Reverse Transcription Polymerase Chain Reaction; RFU: Relative Fluorescence Unit; RIP: RNA Immunoprecipitation; ROS: Reactive Oxygen Species; RPMI-1640: Roswell Park Memorial Institute; RT: Room Temperature; SD: Standard Deviation; SEM: Standard Error of the Mean; sgRNAs: single-guide RNAs; siRNA: Small interfering RNA; SNHG15: Small Nucleolar RNA Host Gene 15; SNORA9: Small Nucleolar RNA, H/ACA box 9; snoRNAs: Small Nucleolar RNA; TCGA: The Cancer Genome Atlas; TNM: Tumor, lymph node, metastasis; UCA1: Urothelial Cancer Associated 1; WT: Wild Type

\section{Acknowledgements}

We thank Dr. Tomás Aragón for his assistance with experimental work, and all patients involved in this study. Authors appreciate the ENCODE project and The Cancer Genome Atlas database for their valuable datasets.

\section{Funding}

This work has been supported by BFU2014-58027-R. This study was part of a $\mathrm{PhD}$ dissertation was supported by Ferdowsi University of Mashhad (No. 41615).

\section{Availability of data and materials}

All data analyzed during current study are included in this published article. Further details could be available upon reasonable request. The RNA-seq data from LoVo cells with knockdown of SNHG15 generated during this study are available at the Gene Expression Omnibus: GSE128998.

\section{Authors' contributions}

MS, MMM and MH designed the experiments and MS mainly did the experiments and wrote the paper. DM performed bioinformatics analyses and JG helped in flowcytometry and in vivo experiments. ARB and SJM contributed in sample processing and management and also helped in data analysis. MH and MMM provided the financial support and supervised laboratorial processes and contributed equally to this work. All authors read and approved the final manuscript.

\section{Ethics approval and consent to participate}

This study was authorized by the Ethics Committee of Ferdowsi University of Mashhad and all CRC patients signed informed consent forms. All the animal studies were performed according to the Research Ethics Committee (CEI) of Navarra University.

\section{Consent for publication}

Not applicable.

\section{Competing interests}

The authors declare that they have no competing interests.

\section{Publisher's Note}

Springer Nature remains neutral with regard to jurisdictional claims in published maps and institutional affiliations.

\section{Author details}

'Department of Biology, Faculty of Science, Ferdowsi University of Mashhad, Mashhad, Iran. ${ }^{2}$ Industrial Biotechnology Reasearch Group, Institute of Biotechnology, Ferdowsi University of Mashhad, Mashhad, Iran. ${ }^{3}$ Department of Gene Therapy and Regulation of Gene Expression, Center for Applied Medical Research, University of Navarra, Pamplona, Spain. ${ }^{4}$ Institute of Health Research of Navarra (IdiSNA), Pamplona, Spain. ${ }^{5}$ Department of Molecular Genetics, Faculty of Biological Sciences, Tarbiat Modares University, Tehran, Iran.

Received: 29 December 2018 Accepted: 7 April 2019

Published online: 24 April 2019

\section{References}

1. Djebali S, Davis CA, Merkel A, Dobin A, Lassmann T, et al. Landscape of transcription in human cells. Nature. 2012;489:101-8.

2. Mattick JS, Makunin IV. Non-coding RNA. Hum Mol Genet. 2006:15:17-29.

3. Jia H, Osak M, Bogu GK, Stanton LW, Johnson R, et al. Genome-wide computational identification and manual annotation of human long noncoding RNA genes. RNA. 2010;16:1478-87. 
4. Cabili MN, Trapnell C, Goff L, Koziol M, Tazon-Vega B, et al. Integrative annotation of human large intergenic noncoding RNAs reveals global properties and specific subclasses. Genes Dev. 2011;25:1915-27.

5. Harrow J, Frankish A, Gonzalez JM, Tapanari E, Diekhans M, et al. GENCODE: the reference human genome annotation for the ENCODE project. Genome Res. 2012;22:1760-74.

6. Mercer TR, Dinger ME, Mattick JS. Long non-coding RNAs: insights into functions. Nat Rev Genet. 2009;10:155-9.

7. Hombach S, Kretz M. Non-coding RNAs: classification, biology and functioning. Adv Exp Med Biol. 2016;937:3-17.

8. Bhan A, Mandal SS. Long noncoding RNAs: emerging stars in gene regulation, epigenetics and human disease. Chem Med Chem. 2014;9: $1932-56$.

9. Vitiello M, Tuccoli A, Poliseno L. Long non-coding RNAs in cancer: implications for personalized therapy. Cell Oncol. 2015;38:17-28.

10. Bartonicek N, Maag JL, Dinger ME. Long noncoding RNAs in cancer: mechanisms of action and technological advancements. Mol Cancer. 2016 15:43-52.

11. Kornfeld JW, Bruning JC. Regulation of metabolism by long, non-coding RNAs. Front Genet. 2014;5:57-64.

12. Brenner H, Kloor M, Pox CP. Colorectal cancer. Lancet. 2014;383:1490-502.

13. Torre LA, Bray F, Siegel RL, Ferlay J, Lortet-Tieulent J, et al. Global cancer statistics, 2012. CA Cancer J Clin. 2015;65:87-108.

14. Xie X, Tang B, Xiao YF, Xie R, Li BS, et al. Long non-coding RNAs in colorectal cancer. Oncotarget. 2016;7:5226-39.

15. Luo J, Qu J, Wu D-K, Lu ZL, Sun YS, et al. Long non-coding RNAs: a rising biotarget in colorectal cancer. Oncotarget. 2017;8:22187-202.

16. Cong L, Ran FA, Cox D, Lin S, Barretto R, et al. Multiplex genome engineering using CRISPR/Cas systems. Science. 2013:339:819-23.

17. Mari'n-Be'jar O, Huarte M. RNA pulldown protocol for in vitro detection and identification of RNA-associated proteins. Methods Mol Biol. 2015;1206: 87-95.

18. Jiang H, Li T, Qu Y, Wang X, Li B, et al. Long non-coding RNA SNHG15 interacts with and stabilizes transcription factor slug and promotes colon cancer progression. Cancer Lett. 2018;425:78-87.

19. Kiss AM, Jády BE, Bertrand E, Kiss T. Human box H/ACA pseudouridylation guide RNA machinery. Mol Cell Biol. 2004;24:5797-807.

20. Thomas LR, Wang Q, Grieb BC, Phan J, Foshage AM, et al. Interaction with WDR5 promotes target gene recognition and tumorigenesis by MYC. Mol Cell. 2015;58:440-52

21. Miramar MD, Costantini P, Ravagnan L, Saraiva LM, Haouzi D, et al. NADH oxidase activity of mitochondrial apoptosis-inducing factor. J Biol Chem. 2001;276:16391-8.

22. Urbano A, Lakshmanan U, Choo PH, Kwan JC, Ng PY, et al. AlF suppresses chemical stress-induced apoptosis and maintains the transformed state of tumor cells. EMBO J. 2005;24:2815-26.

23. Liou G-Y, Storz P. Reactive oxygen species in cancer. Free Radic Res. 2010; 44:479-96.

24. Vahsen N, Cande C, Dupaigne P, Giordanetto F, Kroemer RT, et al. Physical interaction of apoptosis-inducing factor with DNA and RNA. Oncogene. 2006:25:1763-74

25. Yang Y, Junjie $P$, Sanjun C, Ma Y. Long non-coding RNAs in colorectal cancer: progression and future directions. J Cancer. 2017:8:3212-25.

26. Daugas E, Nochy D, Ravagnan L, Loeffler M, Susin SA, et al. Apoptosis inducing factor (AIF): a ubiquitous mitochondrial oxidoreductase involved in apoptosis. FEBS Lett. 2000;476:118-23.

27. Otera H, Ohsakaya S, Nagaura Z, Ishihara N, Mihara K. Export of mitochondrial AIF in response to pro-apoptotic stimuli depends on processing at the intermembrane space. EMBO J. 2005;24:1375-86.

28. Yuste VJ, Moubarak RS, Delettre C, Bras M, Sancho P, et al. Cysteine protease inhibition prevents mitochondrial apoptosis-inducing factor (AIF) release. Cell Death Differ. 2005;12:1445-8.

29. Polster BM, Basañez G, Etxebarria A, Hardwick JM, Nicholls DG. Calpain I induces cleavage and release of apoptosis-inducing factor from isolated mitochondria. J Biol Chem. 2005;280:6447-54.

30. Ravagnan L, Gurbuxani S, Susin SA, Maisse C, Daugas E, et al. Heat- shock protein 70 antagonizes apoptosis-inducing factor. Nat Cell Biol. 2001:3:839-43.

31. Gurbuxani S, Schmitt E, Cande C, Parcellier A, Hammann A, et al. Heat shock protein 70 binding inhibits the nuclear import of apoptosis-inducing factor. Oncogene. 2003;22:6669-78.
32. Tani $\mathrm{H}$, Torimura M. Identification of short-lived long non-coding RNAs as surrogate indicators for chemical stress response. Biochem Biophys Res Commun. 2013;439:547-51.

33. Yang $\mathrm{K}$, Gao K, Hu G, Wen $Y$, Lin C, et al. CTGF enhances resistance to 5-FUmediating cell apoptosis through FAK/MEK/ERK signal pathway in colorectal cancer. Onco Targets Ther. 2016;9:7285-95.

34. Smith ML, Kontny HU, Zhan Q, Sreenath A, Pm O'C, et al. Antisense GADD45 expression results in decreased DNA repair and sensitizes cells to UV-irradiation or cisplatin. Oncogene. 1996;13:2255-63.

35. Moreira MP, Silva LM, Martins WK. The role of GADD45A in resistance to oxidative stress-mediated cell death in human Colon tumor cell lines. Applied Cancer Research. 2009;29:179-84.

36. Wang $L$, Xiao $X$, Li D, Chi $Y$, Wei $P$, et al. Abnormal expression of GADD45B in human colorectal carcinoma. J Transl Med. 2012;10:215.

37. Kim HR, Wheeler MA, Wilson CM, lida J, Eng D, et al. Hyaluronan facilitates invasion of colon carcinoma cells in vitro via interaction with CD44. Cancer Res. 2004;64:4569-76.

38. Misra S, Obeid LM, Hannun YA, Minamisawa S, Berger FG, et al. Hyaluronan constitutively regulates activation of COX-2-mediated cell survival activity in intestinal epithelial and colon carcinoma cells. J Biol Chem. 2008:28314335-44.

39. Fernandez-Medarde A, Santos E. Ras in cancer and developmental diseases. Genes \& cancer. 2011;2:344-58.

40. Haigis KM, Kendall KR, Wang Y, Cheung A, Haigis MC, et al. Differential effects of oncogenic K-Ras and N-Ras on proliferation, differentiation and tumor progression in the colon. Nat Genet. 2008;40:600-8.

41. Shi $H, X u H, L i Z$, Zhen $Y$, Wang B, et al. BAG3 regulates cell proliferation, migration, and invasion in human colorectal cancer. Tumour Biol. 2016;37: $5591-7$

42. Li N, Chen M, Cao Y, Li H, Zhao J, et al. BCl-2- associated athanogene 3 (BAG3) is associated with tumor cell proliferation, migration, invasion and chemoresistance in colorectal cancer. BMC Cancer. 2018;18:793.

43. Rosati A, Ammirante M, Gentilella A, Basile A, Festa M, et al. Apoptosis inhibition in cancer cells: a novel molecular pathway that involves BAG3 protein. Int J Biochem Cell Biol. 2007;39:1337-42

44. Liu K, Hou Y, Liu Y, Zheng J. LncRNA SNHG15 contributes to proliferation, invasion and autophagy in osteosarcoma cells by sponging miR-141. J Biomed Sci. 2017:24:46-56.

45. Ma Y, Xue Y, Liu X, Qu C, Cia H, et al. SNHG15 affects the growth of glioma microvascular endothelial cells by negatively regulating miR-153. Oncol Rep. 2017;38:3265-77.

46. Kong Q, Qiu M. Long noncoding RNA SNHG15 promotes human breast cancer proliferation, migration and invasion by sponging miR-211-3p. Biochem Biophys Res Commun. 2018;495:1594-600.

47. Chen SX, Yin JF, Lin BC, Su HF, Zheng Z, et al. Upregulated expression of long noncoding RNA SNHG15 promotes cell proliferation and invasion through regulates MMP2/MMP9 in patients with GC. Tumour Biol. 2016;37: 6801-12.

48. Zhang JH, Wei HW, Yang HG. Long noncoding RNA SNHG15, a potential prognostic biomarker for hepatocellular carcinoma. Eur Rev Med Pharmacol Sci. 2016:20:1720-4.

49. Ma Z, Huang H, Wang J, Zhou Y, Pu F, et al. Long non-coding RNA SNHG15 inhibits P15 and KLF2 expression to promote pancreatic cancer proliferation through EZH2-mediated H3K27me3. Oncotarget. 2017;8:84153-67.

50. Huang L, Lin H, Kang L, Huang P, Huang J, et al. Aberrant expression of long noncoding RNA SNHG15 correlates with liver metastasis and poor survival in colorectal cancer. J Cell Physiol. 2018. https://doi.org/10.1002/jcp.27456.

\section{Ready to submit your research? Choose BMC and benefit from:}

- fast, convenient online submission

- thorough peer review by experienced researchers in your field

- rapid publication on acceptance

- support for research data, including large and complex data types

- gold Open Access which fosters wider collaboration and increased citations

- maximum visibility for your research: over $100 \mathrm{M}$ website views per year

At $\mathrm{BMC}$, research is always in progress.

Learn more biomedcentral.com/submission 